\title{
Autosomal dominant centronuclear myopathy
}

INSERM

\section{Source}

INSERM. (1999). Orphanet: an online rare disease and orphan drug data base. Autosomal dominant centronuclear myopathy. ORPHA:169189

Autosomal dominant centronuclear myopathy (AD-CNM) is an inherited neuromuscular disorder defined by numerous centrally placed nuclei on muscle biopsy and clinical features of a congenital myopathy. 